\title{
Pengaruh Media Komik terhadap Keterampilan Membaca Cerpen
}

\author{
${ }^{1}$ Muh. Irfan, ${ }^{2}$ Nur Islamiati \\ 12STKIP AL AMIN DOMPU \\ imuh0492@gmail.com
}

\begin{abstract}
Abstrak
Tujuan dari penelitian ini adalah untuk mengetahui pengaruh pengaruh pengaruh media komik terhadap keterampilan membaca cerpen. Adapun jenis penelitian ini adalah penelitian eksperimen. Desain penelitian yang digunakan adalah Quasi Experimental Design dengan jenis Pre-test and Post-test Design. Pengambilan sampel dalam penelitian ini dilakukan dengan teknik sampling purposive, yang diperoleh populasi penelitian adalah siswa SMP IT Wawonduru dengan jumlah sampel sebanyak 32 siswa. Pada analisis data pre-test diperoleh data bahwa kelas kontrol dan kelas eksperimen tidak memiliki perbedaan yang signifikan. Terdapat perbedaan yang signifikan pada hasil post-test siswa kontrol dan eksperimen yang terlihat dari hasil nalisis memperoleh nilai t-hitung sebanyak 8,433 dan memperoleh nilai signifikan sebesar 0,001 dengan $(p<0,05)$. Analisis t-test hasil t-hitung sebesar 5,351 mendapat signifikan sebanyak 0.030 dengan $(\mathrm{p}<0,05)$ sehingga berdasarkan hasil analisis data menggunakan analisis independent sample t-test pada data $\mathrm{N}$-gain terhadap masing-masing kelas dapat disimpulkan bahwasanya terdapat pengaruh media komik pada keterampilan membaca cerpen siswa.
\end{abstract}

Kata Kunci : Media Komik, Keterampilan Membaca, Cerpen

\section{Pendahuluan}

Kurikulum 2013 mata pelajaran Bahasa Indonesia secara umum memiliki tujuan agar peserta didik mampu menyimak, membaca, berbicara, dan menulis (Irsalina, Yuliana, Alamsyah, \& Sultan, 2020). Kompetensi Dasar (KD) dikembangkan berdasarkan empat hal lingkup materi yang saling berhubungan dan saling mendukung pengembangan kompetensi pengetahuan kebahasaan dan kompetensi keterampilan berbahasa (membaca, menyimak, berbicara dan menulis) peserta didik (Istigfara \& Afnita, 2020).

Membaca merupakan salah satu keterampilan yang sangat penting untuk dikuasai siswa. Semakin baik kemampuan siswa dalam membaca maka akan semakin baik pula prestasi akademiknya, begitupun sebaliknya (Ledina \& sumiyadi, Ma'mur, 2020). Membaca memiliki peranan penting dalam dunia pendidikan maupun sosial. Membaca adalah sebuah kegiatan yang dilakukan secara teliti untuk mendapatkan pemahaman isi dan informasi dalam teks bacaan (Yunidar \& Darmawan, 2017). Semua yang diperoleh melalui bacaan itu akan memungkinkan orang tersebut terus memacu daya pikirannya, mempertajam pandangannya, dan memperluas pengetahuannya (Fita, Untari, \& Saputra, 2016). Membaca adalah kegiatan yang dilakukan dan digunakan oleh pembaca untuk mendapatkan pesan yang hendak disampaikan oleh penulis melalui media katakata/bahasa tulis (Fita et al., 2016; Yunidar \& Darmawan, 2017).

Pembelajaran membaca cerpen di sekolah masih banyak siswa yang merasa sulit dalam memahami isi cerpen, khususnya ketika siswa diminta untuk menentukan unsur intrinsik seperti tema (Hartani \& Faturahman, 2018). Masih banyak siswa yang merasa kebingungan dan akhirnya menentukan tema berdasarkan judul yang dibaca. Selain itu, 
siswa merasa kebingungan untuk menentukan struktur pembangun cerpen, seperti menentukan batas antara komplikasi dan resolusi (Hartani \& Faturahman, 2018; Yulisna Risa, 2017). Artinya adalah permasalahan siswa dalam pembelajaran membaca cerpen terletak pada kurangnya pemahaman baca siswa (Puspitasari, 2017). Hal ini membutuhkan sebuah solusi efektif yang mampu menyelesaikan permasalahan tersebut.

Kemampuan mengajar guru memilki pengaruh yang sangat dominan terhadap kemampuan siswa dalam belajar (Affeldt, Meinhart, \& Eilks, 2018). Guru diharuskan untuk menjadi pendidik yang kreatif dan inovatif (Fita et al., 2016). Aspek tersebut menjadi sesuatu yang mencerminkan bagaimana kemampuan guru dalam mengajar guna meningkatkan kemampuan siswa khususnya dalam membaca cerpen (Fita et al., 2016; Ntobuo, Arbie, \& Amali, 2018). Salah satu strategi yang memungkinkan guru dapat meningkatkan kemampuan membaca cerpen siswa adalah dengan menerapkan pembelajaran menggunakan media komik (Affeldt et al., 2018; Ntobuo et al., 2018).

Cerpen adalah karya sastra yang menjelaskan suatu kisah dalam bentuk tulisan yang pendek dan singkat (Tarsinih, 2018). Cerpen dipisahkan sepenggal kehidupan tokoh, yang penuh pertikaian, peristiwa yang mengharukan atau menyenangkan, dan mengandung kesan yang tidak mudah dilupakan (Putri, 2017). Cerpen atau dapat disebut juga dengan cerita pendek merupakan suatu bentuk prosa naratif fiktif (Putri, 2017; Yulisna Risa, 2017).

Penggunaan media pembelajaran yang sesuai dengan materi merupakan sarana untuk mengefektifkan proses penyampaian materi kepada peserta didik (In'am \& Islamiati, 2018). Pembelajaran melalui media komik dapat merangsang dan meningkatkan kemampuan membaca pada peserta didik (Nasrulloh, Hanik, \& Satiti, 2020). Banyak dari kalangan pendidik, masyarakat bahkan orantua siswa memiliki pendapat yang sama terkait media komik yaitu menghadapkan siswa denan media komik memilik dampak buruk terhadap kemampuan siswa baik itu dalam kemampuan afektif, kognitif dan psikomotorik (In'am \& Islamiati, 2018; Ntobuo et al., 2018). Akan tetapi menurut Nasrulloh et al (2020) media komik telah mampu meningkatkan daya tarik belajar siswa dan memiliki dampak positif terhadap pembelajaran karena komik menjadi media yang menarik. Selain itu menurut In'am \& Islamiati (2018) mengungkapkan bahwasanya siswa menjadi lebih termotivasi dan memilki minat dalam belajar setelah menggunakan media komik dalam pembelajaran. Media pembelajaran komik merupakan media bergambar, animasi atau tokoh- tokoh yang berbentuk kartun,untuk memainkan suatu cerita bersambung yang bersifat humor, serta ceritanya ringkas dan menarik perhatian pembacanya (Irawan, Yliani, \& Januardi, 2020) .

Pembelajaran menggunakan media komik dalam pembelajaran dapat menambah daya tarik siswa dalam membaca dan memaknai isi dari cerita yang terdapat dalam komik (Fita et al., 2016). Siswa akan termotivasi untuk belajar lebih giat yang pada akhirnya akan meningkatkan hasil belajar siswa sesuai dengan tujuan dari proses pembelajaran (Fita et al., 2016; Ntobuo et al., 2018). Hal tersebut dapat terlihat ketika guru memberikan pembelajaran dimana siswa terlihat antuas dalam membaca komik yang ditunjukan pada materi cerita pendek (Fita et al., 2016)

\section{Metode Penelitian}

Penelitian ini merupakan penelitian eksperimen dengan desain quasi experimental dengan jenis Pre-test and Post-test Design. Pengambilan sampel menggunakan teknik purposive sampling. Populasi penelitian adalah siswa SMP IT 
Wawonduru dengan jumlah sampel sebanyak 64 siswa. Pada penelitian siswa akan dibagi menjadi dua kelas yaitu kelas kontrol dan kelas eksperimen. Kelas kontrol adalah kelas yang dilakukan menggunakan metode pembelajaran konvensional sedangkan kelas eksperimen menggunakan media komik. Instrumen yang digunakan dalam penelitian ini adalah lembar tes hasil belajar. Selain itu penelitian ini melakukan proses analisis data dengan menggunakan uji-t untuk pengujian hipotesis penelitian. Pengujian hipotesis menggunakan aplikasi SPSS 21 for windows yaitu $t$-test independent.

\section{Hasil dan Pembahasan}

Hasil analisi data pengujian independent sample t-test pada data pre-test, posttest dan $\mathrm{N}$-Gain terhadap kelas eksperimen dan kelas kontrol dapat diperhatikan pada tabel barikut :

Tabel 3.1 Analisis Independent Sample t-test Data Pretest

\begin{tabular}{llccccc}
\hline & Kelompok & $\boldsymbol{N}$ & Mean & Std. Deviation & t-hitung & Sig. \\
\hline \multirow{2}{*}{ Pre.test } & Eksperimen & 32 & 38,5452 & 15,55439 & 0,233 & 0,320 \\
\cline { 2 - 7 } & Kontrol & 32 & 37,5334 & 10,2397 & & \\
\hline
\end{tabular}

Dengan jumlah siswa masing-masing dari kelas eksperimen dan kelas kontrol sebanyak 32 siswa dan dilakukan analisis independent sample t-test pada data pretest diperoleh hasil t-hitung sebesar 0.233. Hasil analisis data juga diperoleh nilai signifikan dari data pre-test terkait kemampuan memebaca siswa sebesar 0,233. Dapat disimpulkan bahawasanya dari hasil analisis data pre-test menggunakan independen ttest tidak memilkiki perbedaan yang signifikan pada signifikan $(\mathrm{p}>0,05)$ anatara siswa yang berada pada kelas eksperimen maupun siswa pada kelas kontrol. Sejalan dengan hasil observasi yang dilakukan oleh Astuti (2018) pada penelitiannya diperoleh hasil observasi awal yang dilakukan adalah minat siswa dalam membaca serta kemampuan siswa dalam kemampuan membaca pemahaman teks bahasa inggris siswa masih kurang. Permasalahan yang sering ditemukan adalah dimana kurangnya minat membaca siswa (Yunidar \& Darmawan, 2017)

Tabel 3.2 Hasil Independent Sample t-test Data Posttest

\begin{tabular}{lllllll}
\hline & Kelompok & $\boldsymbol{N}$ & Mean & Std. Deviation & t-hitung & Sig. \\
\hline \multirow{2}{*}{ Post-test } & Eksperimen & 32 & 95,4831 & 9,64551 & 8,433 & 0,001 \\
\cline { 2 - 7 } & Kontrol & 32 & 72,3137 & 4,96738 & & \\
\hline
\end{tabular}

Data hasil post-test berdasarkan tabel memiliki peningkatan, yang terlihat pada nilai rata-rata yang diperoleh pada masing-masing kelas. Sesuai dengan hasil penelitian Fita et al., (2016) yang telah dipubikasikan, dalam artikelnya ditemukan bahwa terjadi kelas yang diperlakukan dengan penggunaan media komik hasil belajarnya meningkat. Hasil nalisis data post-test menggunakan analisis independent sampel t-test pada masing-masing kelas yaitu kelas eksperimen dan kelas kontrol memperoleh nilai thitung sebanyak 8,433 dan memperoleh nilai signifikan sebesar 0,001. Hasil tersebut menunjukan bahwasanya pada data post-test keterampilan membaca menggunakan analisis data independent t-test pada kelas eksperimen dan kelas kontrol memiliki perbedaan yang sigbifikan dengan $(\mathrm{p}<0,05)$. 
Tabel 3.3 Hasil Independent Sample t-test Data N-Gain

\begin{tabular}{lllllll}
\hline & Kelompok & $\boldsymbol{N}$ & Mean & Std. Deviation & t-hitung & Sig. \\
\hline \multirow{2}{*}{ N-Gain } & Eksperimen & 32 & 92,6236 & 17,5969 & 5,351 & 0,030 \\
\cline { 2 - 7 } & Kontrol & 32 & 77,5788 & 16,3257 & & \\
\hline
\end{tabular}

Hasil analisis independent sample t-test pada data n-gain terhadap kelas eksperimen dan kelas kontrol memperoleh hasil t-hitung sebesar 5,351. Selain itu juga diperoleh hasil signifikan sebanyak 0.030. Berdasarkan hasil analisis data menggunakan analisis independent sample t-test pada data n-gain terhadap masing-masing kelas dapat disimpulkan bahwasanya data n-gain memiliki perbedaan yang signifikan ( $\mathrm{p}<$ 0,05). Selain itu penelitian yang dilakukan oleh Yunidar \& Darmawan (2017) setelah melakukan siklus kedua diketahui bahwa siswa yang tuntas 26 orang siswa dengan presentase ketuntasan klasikal sebesar 100 \% dengan nilai rata-rata 92,3 dan hasil yang didapatkan peneliti menyimpulkan bahwa terdapat peningkatan Kemampuan Membaca Permulaan dengan Menggunakan Media Gambar kelas 1 MIN Buol.

Penggunaan media pembelajaran dapat menjadi salah satu alternatif penyampaian materi yang menarik dan mudah dipahami siswa (Yulia, 2018). Keefektifan media komik digital dalam meningkatkan hasil belajar siswa ranah kognitif, bahwa komik digital efektif untuk meningkatkan hasil belajar (Pardimin \& Widodo, 2017). Penggunaan media pembelajaran diharapkan dapat membantu siswa menguasai materi yang diberikan, sehingga akan meningkatkan hasil belajar siswa.

Media pembelajaran komik juga telah dianggap sebagai sumber pedagogis yang penting, hal tersebut dikarenakan apabila dieksplorasikan di dalam kelas dengan baik, komik dengan fiturnya yang khas memiliki kekuatan besar untuk menceritakan suatu kisah dan menyampaikan pesan, berkontribusi dalam merangsang partisipasi aktif dan kreativitas siswa (Yulia, 2018). Komik memiliki beberapa kegunaan diantaranya 1) dapat motivasi sesuai dengan daya tarik alami manusia terhadap gambar sehingga komik dapat menangkap dan mempertahankan minat siswa; 2) gambar dan teks saling menceritakan sebuah kisah, komik menghasilkan hubungan emosional antara siswa dan karakter dari cerita komik; 3) mengembangkan kemampuan berpikir analitis dan kritis dapat dikembangkan melalui komik; 4) komik dapat membantu siswa dalam memahami topik cerita dan meningkatkan ketertarikan siswa dalam membaca sehingga mampu meningkatkan keterampilan membaca (Astuti, 2018).

Keterampilan membaca merupakan salah satu aspek keterampilan berbahasa yang terdapat dalam kurikulum pembelajaran (Irsalina et al., 2020). Tujuan membaca bagi siswa adalah untuk mendapatkan informasi baru dari sesuatu yang berupa tulisan atau bacaan yang sedang dibaca oleh setiap peserta didik itu. Dengan membaca diharapkan siswa akan memahami makna bacaan yang ingin disampaikan oleh sang penulis. Membaca juga dapat berfungsi bagi para pembaca atau siswa, di antaranya: menambah pengetahuan, untuk menjawab suatu pertanyaan, maupun membuat simpulan dari suatu wacana (Berti, 2019). Untuk mencapai tujuan-tujuan dari membaca, diperlukan adanya pemahaman dalam proses membaca (Rizky, Oktaviany, \& Ayuningrum, 2020). Memahami bahan tertulis bergantung pada karakteristik bahan bacaan itu dan pembacanya. Memahami bacaan dengan baik dapat mencapai apa yang menjadi tujuan dari membaca itu sendiri (Rizky et al., 2020). 
Media komik merupakan salah satu media yang dapat digunakan oleh guru kelas pada saat pembelajaran materi menyimpulkan isi cerita anak (Nasrulloh et al., 2020). Media ini sangat menarik karena selain ada bacaan juga terdapat gambar yang menunjukan isi dari bacaan tersebut. Bacaan yang terdapat pada komik ini ditujukan kepada siswa untuk dibaca dan dipahami. Sedangkan gambar yang terkandung dalam media, memberikan kemudahan bagi siswa untuk memahami makna yang tersirat pada cerita (Nasrulloh et al., 2020; Ntobuo et al., 2018). Terpadunya antara bacaan cerita dan gambar, akan mempermudah siswa dalam mencerna isi dari cerita yang dibaca sehingga siswa mampu menyimpulkan isi dari cerita yang telah dibaca dan dipahami (Fita et al., 2016).

\section{Simpulan dan Saran \\ Simpulan}

Simpulan penelitian yang diperoleh seteah melakukan penelitian dan analisi data adalah sebagai berikut:

1) Pada analisis data pre-test diperoleh data bahwa kelas kontrol dan kelas eksperimen tidak memiliki perbedaan yang signifikan

2) Terdapat perbedaan yang signifikan pada hasil post-test siswa kontrol dan eksperimen yang terlihat dari hasil nalisis memperoleh nilai t-hitung sebanyak 8,433 dan memperoleh nilai signifikan sebesar 0,001 dengan $(p<0,05)$.

3) Analisis t-test hasil t-hitung sebesar 5,351 mendapat signifikan sebanyak 0.030 dengan $(\mathrm{p}<0,05)$ sehingga berdasarkan hasil analisis data menggunakan analisis independent sample t-test pada data n-gain terhadap masing-masing kelas dapat disimpulkan bahwasanya terdapat pengaruh media komik pada keterampilan membaca cerpen siswa.

\section{Saran}

Penelitian yang kami lakukan masih sangat jauh dari kesempurnaan oleh sebab itu bagi pembaca semoga terunggah hatinya untuk melakukan penelitian yang relevan agar proses pembelajaran matematika khususnya di Sekolah Dasar semakin membaik serta tercapainya tujuan pendidikan. 


\section{Daftar Pustaka}

Affeldt, F., Meinhart, D., \& Eilks, I. (2018). The Use of Comics in Experimental Instructions in a Non-formal Chemistry Learning Context. International Journal of Education in Mathematics, Science and Technology, 6(1). https://doi.org/10.18404/ijemst.380620

Astuti, P. (2018). Peningkatan Kemampuan Membaca Pemahaman Bahasa Inggris Melalui Media Komik Berbahasa Inggris Pada Siswa Kelas Viii Mts. PERSPEKTIF Ilmu Pendidikan, 32(1), 1-7.

Berti, A. (2019). Peningkatan Keterampilan Membaca Cerpen Dengan Metode P2R Dan Berpikir-Berpasangan-Berbagi. Jurnal Pendidikan Tambusai, 3(6), 12341242.

Fita, M., Untari, A., \& Saputra, A. A. (2016). Keefektifan Media Komik Terhadap Kemampuan Membaca Pemahaman Pada Siswa Kelas IV SD. Mimbar Sekolah Dasar, 3(1), 29-39. https://doi.org/10.17509/mimbar-sd.v3i1.2354

Hartani, A., \& Faturahman, I. (2018). Peningkatan Kualitas Pembelajaran Menyimak Cerpen Melalui Model Picture And Picture Berbantuan Media Cd Cerita Pada Siswa Kelas V Sekolah Dasar. Jurnal Kredo, 2(1), 17-38.

In'am, A., \& Islamiati, N. (2018). An Analysis of Students ' Mathematical Disposition using the Comic Media in Learning Geometry. In Advances in Social Science, Education and Humanities Research (Vol. 231, pp. 212-215).

Irawan, L., Yliani, E., \& Januardi. (2020). Pengaruh Media Pembelajaran Komik Terhadap Hasil Belajar Siswa Akuntansi Di SMK PGRI 1 Palembang Tahun Pelajaran 2019/2020. Jurnal Neraca, 3(1), 99-107.

Irsalina, Y., Yuliana, R., Alamsyah, T. P., \& Sultan. (2020). Primary: jurnal pendidikan guru sekolah dasar. Pengembangan media busy book berbasis metode global pada pembelajaran membaca permulaan, 9(4), 527-539.

Istigfara, T., \& Afnita. (2020). Model Pembelajaran Kooperatif Tipe Think Pair Share (Tps) Dalam Pembelajaran Membaca Pemahaman Cerpen. Jurnal Pendidikan Bahasa Dan Sastra Indonesia, 9(1).

Ledina, H., \& sumiyadi, Ma'mur, S. (2020). Model Know , Want To Know , Learned ( KWL ) Dalam Pembelajaran Membaca Cerita Pendek Siswa SMP Kelas IX. Bahterasia : Jurnal Ilmiah Pendidikan Bahasa Dan Sastra Indonesia, 1(3), 101108.

Nasrulloh, M. F., Hanik, S., \& Satiti, W. S. (2020). E-Comic Learning Media Based Problem Based Learning In Subject of Linear Equation System. Jurnal Hipotenusa, 2(1).

Ntobuo, N. E., Arbie, A., \& Amali, L. N. (2018). The Development Of Gravity Comic Learning Media Based On Gorontalo Culture. Jurnal Pendidikan IPA Indonesia, 7(2), 246-251. https://doi.org/10.15294/jpii.v7i2.14344

Pardimin, \& Widodo, S. (2017). Development Comic Based Problem Solving in Geometry. International Electronic Journal of Mathematics Education, 12(3).

Puspitasari, A. (2017). Kemampuan Menulis Cerpen ( Studi Korelasional pada Siswa SMA Negeri 39 Jakarta ). Jurnal SAP, 1(3), 249-258.

Putri, D. (2017). Peningkatan Keterampilan Menulis Cerita Pendek Dengan Menggunakan Teknik Copy The Master Pada Mahasiswa Pendidikan Bahasa dan Sastra Indonesia STKIP Rokania. Jurnal Pendidikan Rokania, 2(1), 30-47.

Rizky, A. V., Oktaviany, V., \& Ayuningrum, S. (2020). Upaya Meningkatkan Kemampuan Membaca Cerpen melalui Model Pembelajaran Cooperative 
Integrated Reading and Composition. In Prosiding Seminar Nasional Pendidikan STKIP Kusuma Negara II (pp. 298-304).

Tarsinih, E. (2018). Kajian terhadap nilai-nilai sosial dalam kumpulan cerpen "rumah malam di mata ibu" karya alex r. Nainggolan sebagai alternatif bahan ajar. Bahtera Indonesia: Jurnal Penelitian Pendidikan Bahasa Dan Sastra Indonesia, 3(2), 70-81.

Yulia, N. (2018). Developing Teaching Materials Using Comic Media to Enhance Students ' Mathematical Communication. In IOP Conf. Series: Materials Science and Engineering. https://doi.org/10.1088/1757-899X/335/1/012110

Yulisna Risa. (2017). Kontribusi kemampuan memahami cerpen terhadap keterampilan menulis cerpen siswa kelas XI SMA Negeri 4 Padang. Jurnal gramatika Jurnal: Jurnal Penelitian Bahasa Dan Sastra Indonesia, 2(2), 72-83.

Yunidar, I., \& Darmawan. (2017). Meningkatkan Kemampuan Membaca Permulaan Dengan Menggunakan Media Gambar Kelas 1 di Min Buol. Jurnal Kreatif Online, 5(4), 1-14. 